\title{
THE PROBLEM OF APPROACH, METHOD AND TECHNIQUE IN THE SCIENTIFIC STUDIES: AN ALTERNATIVE INTERPRETATION
}

\author{
Ercan TOMAKİN*
}

\begin{abstract}
The aims of this study are a) to show the knowledge taken from sources other than science can be used in the scientific research, b) to indicate that the types of research cannot be put into categories in a unchangeable way, but they can take place either under qualitative or quantitative approach, yet this depends on researchers' aim(s) and c) to draw researchers' attention in writing the methodology section of their papers. The study used qualitative approach and the data of the study was collected through the analysis of the written documents which were books about undertaking scientific research and published articles. The analysis has indicated that authorities, individual experience, the old and traditions regarded as non-scientific sources of information could also be useful in undetaking scientific research. Besides, it is seen that any types of research (case study, action research, etc.) can be undertaken qualitatively or quantitatively. In addition, is it seen that some of the published articles do not mention clearly about one or two of the following "approach, method and technique" terms.
\end{abstract}

Key words: scientific research, information sources, qualitative and quantitative research, methodology

\footnotetext{
Assist. Prof. Dr., Yüzüncü Yıl Universtiy, Education Faculty, Foreign Languages Department, English Language and Education, etomakin@yyu.edu.tr.
} 


\section{SUMMARY}

Desire of knowing, interest, drive of wonder, etc. cause people to investigate objects, environments, events and phenomena. Knowledge emerges after reliable and valid investigations and these are only possible through scientifically undertaken research. Hence solid information depends on scientific research which is usually undertaken in two types. These are pozitivism and post-positivizm which have contrary arguments from past to present time. Therefore, knowledge, research and research types are three interrelated phonemena.

The topic of knowledge was much discussed in philosohy and science. In the former the nature of the knowledge is explained in terms of epistemology or the philosophy of mind. In this view, the first group concentrates on the nature of knowledge and the second concentrates on the nature of the knower (Speake ve Mitchell (1979). Scientific knowledge has the following features: In Karakaş' (1988) view, cited in Erkuş, (2005, 2728) "observation, measurement, transmition, repetition and control" are the features of the science. To Karasar $(2005,12)$ the nature of the science is "phenomenon, systematic, reasonable, generaliseable, universal, summative, written, sound but relative". According to McMillan and Schumacher 1984) cited in Balc1 (1997, 3) "objectivity, completeness, validation, simple explanation, experiment and probability thinking" are the features of science.

Knowledge emerges as a result of research which can be undertaken qualitatively, quantitatively or a mixture of both. Although the scientists have concensus on the features of science and scientific knowledge, it is difficult to see an agreement about the ways of undertaking scientific research and classifying the science into various disciplines.

Research is undertaken duductively in Aristo's understanding and it is carried out inductively in Bacon's understanding (Cohen and Manion, 1996). To Robson $(1995,18)$ the words positivism, quantitative, scientific, and experimental are used interchangeable to mean deductive. Similarly, he also means that the words interpretive, ethnographic are interchangeably used to mean inductive. In this context quantitative model is usually considered as scientific and qualitative is not considered as so.

Although discussion about the ways of undertaking research and its classification continues, the foreign data-bases (e.g. EBSCO, ERIC, BEI, etc.) use the words qualitative and quantitative in explaining the methodology section of the undertaken research. Hence qualitative means the explanation of the research mostly by using words and sentences in the written form. Quantitative means explanation of research by numbers, tables, figures and statistic calculations. 
The analysis of the written works on Undertaking Scientific Research in Turkey, for example, (Karasar, 2005; Erkuş, 2005) indicates that the olds, authorities, individual experiences, traditions and science are regarded as the sources of information, yet the knowlege taken from other sources except science is not seen sufficient. Instead, the information sources other than science can be looked from a wide angle. Similarly, some of the written works, for example (Ekiz, 2003; Çepni, 2005) on Undertaking Scientific Research put the types of research (case study, action research, etc.) into a certain category. Yet in analysing the western-database it is seen that the types of research can take place under qualitative or quantitative classification. Lastly, it is seen in some of the published articles that one or two of the key terms -approach, method and technique- have not been stated clearly in the medhodology section.

Method: This study, as will be explained under the 3rd article, used qualitative approach, using case study method. Here the word qualitaive is used to mean the explaination of the research by using words and sentences in the written form. In a case study the case is researched, analysed, tested, etc. Since the case is defined as "an integrated and bounded system" in the research literature (Stake 1995, 2), it can be claimed that every thing which is bounded and unique is a case. The researcher either selects a pre-defined case (e.g. school, student, classroom, etc.) or the researcher himself/herself identifies the boundary of the study (e.g. success, examination fear, etc.) in the case studies (Bell et al. (1984, 94-95. It is wrong to translate the case study as a (special) event, situation, etc.

The case of this study is scientific research, the written works and published articles on undertaking scientific research. This is because I limit my focus with scientific research. The technique used in the study is the comparision of the views revealed in these works.

Results: It is seen that there is a concensus about the sources of information in the literature and these are the old, authorities, individual experiences, traditions and science. The information coming from these sources except science are not regarded as scientific. It is also seen that nobody denies the importance of science and scientific research. Yet this study indicates that although the information coming from the old, individual experiences, authorites, etc., hese sources can also be useful in undertaking scientific research.

Conclusion: the question arises as to being objective and neutral to the sources of information not only in scientific research, but also in our social and daily life. It seems that not only in our daily life but also in the scientific studies we get and use information from the old, traditions, and experience. 


\title{
BİLIMSEL ÇALIŞMALARDA YAKLAŞIM, YÖNTEM VE TEKNIK PROBLEMİ: ALTERNATIF BİR YORUM
}

\author{
Ercan TOMAKİN*
}

\begin{abstract}
ÖZ:
Bu çalışmanın amacı, a) bilim ve bilimsel bilgi dışında tutulan bilgi kaynaklarının da bilimsel çalışmalarda kullanılabileceğini, b) araştırma türlerinin sabit ve değişmez şekilde ya nitel ya da nicel yaklaşımın altında değil, her iki yaklaşımın altında yer alabileceğini ve bunun da araştırmacının amacına/hipotezine bağlı olduğunu, ve c) bilimsel çalışmalarda kullanılan yaklaşım, yöntem ve tekniklerin belirtilmesi ve yöntem bölümlerinin yazılmasında, araştırmacıların dikkat etmeleri gereken hususları açıklamaktır.

Çalışmada nitel yaklaşım kullanıldı ve çalışmanın verileri bilimsel araştırma konusunda yazılmış kaynakların ve yayımlanmış makalelerin incelenmesi sonucu toplandı. Yapılan incelemede, bilimsel yolun dışında tutulan, ancak bilgi kaynağı olarak kabul edilen otoritelerin, yaşlıların, geleneklerin ve bireysel tecrübelerin de bilgi edinmede ve bilimsel çalışmaları gerçekleştirmede etkili olduğu görülmüştür. Ayrıca, araştırma türlerinin (vaka/durum araştırması, aksiyon araştırması, vd.) nitel veya nicel gerçekleştirildiği görülmüştür. Son olarak, yayımlanan bazı çalışmalarda, araştırmada kullanılan yaklaşım, yöntem veya teknikten bir veya birkaçından hiç bahsedilmediği görülmektedir. Bu çalışma, adı geçen amaçlara ve sorunlara çözüm önerileri sunmaktadır.
\end{abstract}

Anahtar Kelimeler: bilimsel araştırma, bilgi kaynakları, nitel ve nicel araştırma, yöntem.

*Yrd. Doç. Dr., Yüzüncü Yıl Üniversitesi, Eğitim Fakültesi, Yabancı Diller Blm, İngiliz Dili ve Eğitimi Anabilim Dalı, etomakin@yyu.edu.tr 


\section{GİRIȘ}

Bilme istemi, ilgi, merak gibi etkenler insanların, çevresini, olayları, olguları, nesneleri araştırma ve incelemesine neden olur. Doğru, güvenilir ve geçerli bilgiler ise bilimsel olarak yapılan araştırmalarla olanaklıdır. Bilimsel araştırma yapma konusunda ise önceden beri devam eden iki karşıt argüman vardır, bunlar pozitivism ve post-pozitivismdir. Bu bağlamda, bilginin ortaya çıkma şeklini belirleyen bilimsel araştırma ve bu araştırma türlerinin birbiriyle ilişkisini açıklamak gerekir.

Bilginin kaynakları çok çeşitlidir. Bunlar kısaca, bilim, gelenekler, otoriteler, bireysel deneyimler vs. şeklinde sıralanabilir. Bilgi kaynaklarının bilimselliği konusunu açıklamadan önce, felsefede ve bilimde, bilginin nasıl tarif edildiğini kısaca belirtmek gerekir.

Bilginin tanımı konusunda felsefi ekollerin yaklaşımı farklılık göstermektedir. Örneğin, idealistler, varlıkların mutlak gerçekliği bulunmadığına, onları zihnin var ettiğine inanırlar. Eflatun, duyular yoluyla elde edilen bilginin kesin olmadığı görüşündedir. Ona göre gerçek bilgi tek başına aklın ürünüdür. $\mathrm{O}$, gerçek bilgiyi fizik alemde değil, idea'larda arar. Kant da zihnin, duyulardan aldığı bilgiyi aktif olarak düzenleyip anlamlandırdığını düşünür (Tozlu, 1997). Realistlere göre ise varlıklar duyular aleminde oldukları gibi vardırlar. Onlara göre gerçeği insan zihni ortaya koymaz. Aksine, zihin gerçeği idrak eder ve kabullenir. Çünkü varlıklar zihinden bağımsız olarak vardırlar (Tozlu, 1997, 52). Pragmatistler ise bilgiyi insan ile çevresi arasındaki bir ilişki olarak değerlendirirler. Onlara göre insan zihni pasif ve alıcı değil, aktif ve yaratıcıdır. İnsan, bilgiyi pasif şekilde alan değil, onu yapandır. Örneğin W. James bir fikrin doğruluğunu o fikri benimseyenlerin tatmin derecesine bağlar. J. Dewey ise bilginin doğruluğunun bilimsel testlerle ortaya konacağını düşünür (Tozlu, 1997, 58).

Bilim insanları arasında bilimsel bilgi kabul gördügünden, bilimin özellikleri aynı zamanda bilimsel bilginin özelliklerini yansıtmaktadır. Bilimsel bilginin özellikleri şu şekilde sayılmaktadır: "Tarafsızlık, doğru ölçü, kanitlanma, genelleyici ve mevcut olanla uğraşma" bilimin özellikleridir (Türkdoğan,1995, 15). "Nesnellik, tamlık, doğrulama, basit açıklama, ampirizm ve olasılıklı düşünme" bilimin nitelikleridir (McMillan ve Schumacher 1984, 5; Balcı, 1997,3). Çağdaş bilimin özellikleri "çeşitlilik, süreklilik, yenilik ve ayıklamadır" (Çepni, 2005, 3). "Gözlenebilirlik, ölçülebilirlik, iletilebilirlik, tekrarlanabilirlik ve sağdanabilirlik" bilimin ölçütleridir (Karakarş, 1988; Erkuş, 2005, 27-28). Bilim "olgusaldır, sistemlidir, akılcıdır, genelleyicidir, evrenseldir, birikimlidir, kayıtlıdır, sağlam ancak görelidir" (Karasar, 2005, 12). Son olarak, Yıldırım ve Şimşek ise $(2005,31)$ "yükselen ve düşüşteki paradigmaların özelliklerini" karşılaştırarak bilimin özelliklerini açıklamaktadır. 
Netice olarak çağdaş bilimsel görüş ile bazı felsefi ekollerin bilgi anlayışının örtüştüğü görülmektedir. Şöyle ki bu ekollerde, duyu, zihin, idrak, alg1 gibi farklı yollarla elde edilen bilgi gerçeği yansıtmamaktadır. Çağdaş anlayışta ise bilgi tekrarlanabilir, genellenebilir, ampirik, gözlenebilir, vs. özelliklere sahiptir. Bu bağlamda, bilginin ne olduğu konusu önemli olduğu kadar, bilginin ortaya çıkmasını sağlayan bilimsel araştırmaların yapılış şekilleri de önemlidir. Çünkü bilimsel bilgi, bilimsel araştırmalar sonucu ortaya çıkar. Ancak, bilimsel araştırmaların yapılış şekilleriyle ilgili bilim insanları arasında bir fikir birliği yoktur.

Bilimsel araştırmalar, Aristo'cu anlayışa göre tümden gelim (deductive) yaklaşımına göre, Bacon'cu anlayışa göre ise tüme varım (inductive) yaklaşımına göre yapılır (Cohen ve Manion, 1996). Robson $(1995,18)$ ise tümden gelim, pozitivist, nicel, bilimsel ve deneysel kavramlarının aynı anlamda kullanıldığını, tüme varım anlamında ise nitel, yorumlayıcı, etnografik gibi kavramların kullanıldığını belirtmektedir.

Bilimsel araştırmalar, Balcı'ya (1997) göre "ampirik ve teorik"; Karasar'a (2005) göre "tarama ve deneme"; Erkuş'a (2005) göre ise "ilişki arayan ve ilişki aramayan” şeklinde ayrılmaktadır. Ekiz (2003), (Kuş, 2003) ve Çepni (2005) ise araştırmaları nicel (pozitivist) veya nitel (postpositivist) olarak ikiye ayırmaktadırlar. Türkdoğan (1995, 20-21) araştırmaların Viyana okulu ile birlikte "doğrulanabilirlik" temeline, Karl Popper ile "yanlışlanabilirlik" temeline oturduğunu, ancak Thomas Kuhn'la birlikte "her teorinin kendine yöneltilen eleştirileri ve karşı örnekleri gene kendi temelinde cevaplandırarak ve gerekli düzeltmeleri yaparak, geçerliliğini koruyabileceğini” belirtmektedir.

Bilimsel araştırmaların yapılış şekli ve yöntemiyle ilgili tartışmalar devam etmesine rağmen, yabancı veri kaynaklarında (örnek, EBSCO, ERIC; $\mathrm{BEI}$, vs.) yapılan araştırmaların yöntemlerinin yazımında nitel (qualitative) ve nicel (quantitative) sözcüklerinin kullanıldığı görülmektedir. Pozitivizm olarak da bilinen nicel araştırma süreci hipotezle başlar, veri toplanır, analiz edilir ve veriden çıkan sonuç hipotezi destekler veya çürütür. Araştırmadan çıkan sonuç evrene genellenir. Bu nedenle de nicel bulguların güçlü olduğu iddia edilir. Nitel araştırma sürecinde veriler toplanır, analiz edilir ve ortaya çıkan sonuç kuram (hipotez) olarak ifade edilir. Nitel araştırma sonuçlarının göreceli olduğu ve evrene genellenemediği iddia edilir (Robson, 1995; Karasar, 2005). Nitel araştırmalar çoğunlukla sözcüklerle, tümcelerle ve yazıyla anlatılır, nicel araştırmalar ise rakamlarla, çeşitli hesaplamalarla ve istatistiksel olarak anlatılır (Robson, 1995, 307).

Nicel araştırmalarla sağlam ve evrene genellenebilir bilgi, nitel araştırmalarla da zayıf ve evrene genellemez bilgi üretilir denilmesine rağmen, sosyal bir olay, durum, olgu, vs. nicel yaklaşımla araştıııldığında, 
ortaya çıkan sonuç (bilgi) her zaman geçerlidir ve değişmez geçerliliğe sahiptir denilemez. Bilindiği gibi, sosyal olaylar görecelidir; yere, zamana, kişiye, duruma, vs. göre değişebilmektedir. Aynı şekilde, madde, element, 1ş1k, sıcaklık, atom, proton, hücre, çekirdek vb. konuların nitel yolla araştırılması da araştırma sonuçlarının zayıflığını göstermez. Bilimsel araştırmalarda önemli olan ve bu güne kadar pek değinilmeyen nokta şu şekilde açıklanabilir:

Bilimsel araştırmanın konusu (madde, olay, olgu, vs.) değişmez ve sabit özelliğe sahipse, araştırmanın nitel yapılması, araştırma bulgularının zayıflığını göstermez. Değişmez özellikteki maddeler (örnek, taş, demir, vs.) nicel yolla araştırılırsa, şöyle bir durum ortaya çıkmaktadır. Nicel araştırma hipotezle başladığı için, hipotezin doğrulanmaması durumunda, araştırmacı hipotezini destekleyinceye kadar araştırmasına devam eder. $\mathrm{Bu}$ durumda araştırmanın birden çok, belki onlarca kez yapılma olasılığ 1 vardır. Ancak, değişmez özelliğe sahip maddeler (araştırma konuları) nitel yolla araştırılırsa, toplanan veriden sonuç (hipotez) çıkarılacağı için, araştırmanın kısa sürede ve ekonomik olarak bitme olasılı̆̆ 1 vardır.

Nitel ve nicel araştırma sonuçlarının zayıf, kuvvetli, genellenebilir ve genellenemez olması konusunda başka bir tespit yapmakta yararlı olacaktır. Örneğin, su, deniz kenarında 100 santigrat derecede kaynar, sıfır (0) derecede donar ve donan su genleşir. Benzer şekilde, isınan hava genleşir, ısınan tren rayları, elektrik kabloları bir miktar uzar. Bu sayılanlar, suyun, havanın, demirin, vs. değişmez (sabit) özellikleri midir, yoksa nicel araştırmanın üstünlükleri midir? Bu noktanın iyi ayırt edilmesi gerekir. Su ile ilgili kaynama, donma, buharlaşma, vs. noktalarına ait özellikler sadece su için geçerlidir, başka bütün sıvılar için değildir. Su, tek başına bir maddedir ve tek başına araştırılıp analiz edilmektedir. $O$ halde, sosyal bilimlerin konusu olan öğrenci (ler), insan(lar), olay(lar), olgu(lar), vs. teker teker ele alınıp araştırılmalıdır. Yani, su, bir sıvı olmasına rağmen, su ile ilgili özellikler başka sıvılara genellenemediği gibi, bir öğrenciyle ilgili olan veriler/bulgular da başka öğrencilere genellemek o kadar yanıltıcı olur. Başka bir ifadeyle, 30 değişik sıvıyı bir kaba doldurup ortak kaynama noktasını nicel olarak bulmak ne kadar doğru ise, bir sınıftaki 30 değişik öğrencinin ortalama başarı oranını nicel olarak bulmak da o kadar doğrudur.

Netice olarak, bilgi, bilginin üretilmesini sağlayan bilimsel araştırma ve yöntemleri konuları birbiriyle ilişkilidir. Bu üç konu ülkemizde yayımlanan kitap ve makalelerde şu şekilde açıklanmaktadır: Bazı araştırmacılara göre (örneğin, Karasar, 2005; Erkuş, 2005) otoriteler, yaşlılar, bireysel tecrübeler, gelenekler ve bilim, bilgi kaynağı olarak görülür, ancak bilimin dışında tutulan diğer bilgi kaynakları ve bunlardan elde edilen bilgiler yeterli 
görülmez. Bunun yerine, bu kaynaklara farklı bir bakış açısıyla bakılabilir. Hatta bu kaynaklardan elde edilen bilgiler, bilimsel araştırmalarda da kullanılabilir. Yine bazı kaynaklara göre (örneğin, Ekiz, 2003; Çepni, 2005), araştırma türleri (vaka/özel durum araştırması, aksiyon araştırması, tarihsel araştırma, vd.) belli bir araştırma yaklaşımının altında sınıflandırılmaktadır. Ancak batılı veri tabanları incelendiğinde, araştırma türlerinin her iki (nitel veya nicel) yaklaşım altında yer alabildiği görülmektedir. Son olarak, yayımlanan araştırmaların bazılarında, araştırmada kullanılan yaklaşım, yöntem ve teknikten bir veya ikisinden hiç bahsedilmemektedir.

\section{YÖNTEM}

\section{Amaç}

Bu çalışmanın amacı:

a) Bilimsel kabul edilmeyen bilgi kaynaklarının bilimsel araştırmalarda kullanılma durumunu;

b) Araştırma türlerinin sabit veya değişken şekilde sınıflandırılmasını;

c) Araştırmalarda kullanılan ancak bazen belirtilmeyen yaklaşım, yöntem ve teknik konularını açıklamaktır. Bu bağlamda, araştırmayı yönlendiren sorular şunlardır:

1. Bilimsel yöntemin dışında tutulan bilgi kaynakları, alternatif bir açıdan bakılarak, bilimsel çalışmalarda kullanılabilir mi?

2. Bilimsel araştırma türlerinin (aksiyon araştırması, örnek/vaka araştırması, tarihsel araştırma, vd.) bilimsel yaklaşımlar altında sınıflandırılması sabit mi yoksa değişken midir?

3. Yayımlanan bilimsel araştırmaların yöntem bölümlerinde belirtilmeyen (yaklaşım, yöntem, teknik) bölüm(ler) bulunmakta midir?

\section{Veri Toplama Aracı}

$\mathrm{Bu}$ çalışmanın verileri, bilimsel araştırma konusunda yazılmış kitaplar ve yayımlanmış makalelerden toplanmıştır. Bu kaynakların bir kısmı Türkiye'deki bilim insanları tarafından yazılan, diğer kısmı ise İngiltere ve Amerika'da yazılan kitaplardan oluşturmaktadır. Türkiye'de yazılan kitapların çoğunlukla İngilizce yazılmış kaynaklardan yararlandığ görülmektedir. Ayrıca hem ülkemizde hem de yurt dışında (İngiltere) yayımlanmış makalelerin metodoloji bölümleri incelenerek veri toplanmıştır. 


\section{Yaklașım}

$\mathrm{Bu}$ çalışma, aşağıda üçüncü maddede ayrıntılı olarak açıklanacağı gibi, nitel yaklaşım kullanılarak yapılmıştır. Yaklaşım başlığı altında, ülkemizde yazılan makalelerde genellikle ayrı bir bölüm bulunmamaktadır. Robson'un $(1995,307)$ belirttiği gibi, nitel araştırma, çalışmanın yazıyla, sözcüklerle ve tümcelerle ifade edilmesi anlamında kullanılmıştır. Ayrıca, nitel yaklaşım, çalışmanın, veri toplanması, analiz edilmesi ve sonuçların bulunması sürecinde gerçekleştirildiğini göstermektedir.

\section{Yöntem}

Araştırmanın yöntemi (türü) ise örnek/vaka/durum araștırmasıdır. İngilizce yazılmış bilimsel araştırma ile ilgili kaynaklarından Türkçe'ye vaka/örnek/durum çalışması olarak çevrilen araştırma türünün "case study" (CS) olduğu görülür (Stake, 1995). Bir CS'de ise, "case" araștırılır, incelenir, test edilir. "Case" ise "sınırları belli (a bounded system) ve bütün bir sistem" (unique, entegrated system) olarak tanımlanmaktadır (Stake 1995, 2). Örnek, öğrenci, öğretmen, okul, sınıf, başarı, vs. birer "case"dir. CS konusu doğrudan çevrildiği için, vaka/örnek/durum çalışması olarak çevrilmiştir. İngilizce "case study" kelimelerini doğrudan çevirerek veya CS'yi özel bir durum, özel bir vaka, vs. şeklinde ifade etmek doğru değildir. Sınırlı ve bütün olan her şey ya bir "case"dir ya da CS'nin konusu olabilir. CS'de, ya sınırları önceden belirli bir "case" seçilir (örnek, okul, öğrenci, sınıf, vs.) ve bu seçilen "case" araştırılır; ya da araştırmacı çalışmasının sınırlarını kendisi belirler (Bell ve diğerleri 1984, 94-95). Örneğin, araştırmacı, bir okuldaki başarı ile ilgili araştırmanın sınırlarını öğrenciler, öğretmenler, veliler, vs.den aldığı cevaplarla sinırlayabilir (çizebilir). Bu çalıșmanın case'ini ise bilimsel araștırma yapma konusu ve bu konuda yazılmış kitap ve makaleler oluşturmaktadır. Çünkü çalışmamız bu konu ile sınırlandırılmıştır.

Bilimsel bilginin geçerli, güvenilir, tekrarlanabilir ve genellenebilir olduğu bilinmektedir. Bilimsel araştırmalardaki bulguların başkaları tarafindan tekrar edilebilmesi için metot bölümünde veri toplama ve veri analizinin açık olarak yazılması gerekir. Ancak bazı makalelerde yöntem kısmının ayrıntılı şekilde yazılmadığı görülmektedir. Bu çalışmada yaklaşım, yöntem ve teknik konularını ayrıntılı şekilde ortaya koymadığı düşünülen eserler (kitap ve makaleler) incelenmiştir. 


\section{Teknik}

Nitel araştırmada veri analizi karşılaş̧ırma, gruplama, modelleme, benzetme şekillerinde yapılmaktadır (Miles ve Huberman, 1994). Bilimsel araştırma yöntemleri konusunda yazılmış eserlerdeki (kitap-makale) kuramlar ile yayımlanmış araştırma makalelerinin yöntem bölümlerinin karşılaştırılması bu çalışmanın tekniğini oluşturmuştur. Yani, bilimsel araştırma yazınındaki görüşlerin incelenen makalelerde ne ölçüde yerine getirildiği çetele grafiği şeklinde değerlendirilmiştir.

\section{Sinurlılıklar}

Bu çalışmada, bazı bilimsel yayınlarda karşılaşılan yaklaşım, yöntem ve teknik konularına ilişkin eksiklikler incelenmektedir. Ancak Sosyal Bilimler Enstitüleri ve Eğitim Fakülteleri tarafından yayımlanan bütün bilimsel yayınları incelemek zaman ve kaynak bakımından olanaklı değildir. $\mathrm{Bu}$ nedenle, çalışmamız, bilimsel araştırma konusunda öne çıkan temel kitaplar ile kaynakçada atıf yapılan ve yaklaşım, yöntem ve teknik sorunu olduğu düşünülen makalelerin incelenmesiyle sınırlandırılmıştır.

\section{BULGULAR VE YORUM}

\section{Bilgi Kaynakları ve Bilim}

Bilgi, dünyamızın global köy haline geldiği internet çağında, hızlı bir şekilde yayılır ve çeşitli kaynaklardan elde edilebilir. Bu bilgi kaynaklarının bilimde kullanılıp kullanılmamasına ilişkin görüşler farklılık gösterir. Karasar'a (2005, 3-5) göre bilgi kaynakları "rasyonalizm ve ampirizmdir" ve temelleri Viyana'da atılan empirist yaklaşıma "modern deneycilik ve bilim felsefesi" denilmektedir. Yine Karasar (2005, 5-7) bilginin kaynaklarını "önceki uygulamalar (gelenekler/emsal), otoriteler, bireysel tecrübeler ve bilim" olarak belirttikten sonra en doğru ve en güvenilir bilginin bilimsel yolla elde edilebileceğini belirtmektedir.

Erkuş'a (2005, 22-23) göre de bilginin kaynağ1 "gelenekler, otoriteler, bireysel deneyimler ve doğaüstü güçlerdir". Ona göre bilgiye, rasyonel yaklaşımla (akıl yürütme), görgül (empirik) yaklaşımla ve deneysel yaklaşımla ulaşılabilir. "Bilimsel yaklaşım hem mantıksal hem de görgül doğrulamanın birlikte bulunduğu yaklaşımdır" (Erkuş, 2005, 24). Pozitivizmde, bilgi, "olgu ya da yasalar olarak kabul edilebilecek doğrulanmış hipotez"lerden oluşur. Post-pozitivizmde ise bilgi, olgu ya da yasa gözü ile bakılabilecek yanlışlanamayan hipotezlerden oluşur (Kuş, 2003, 110). Türkdoğan (1995, 20-21), yukarıda belirtildiği gibi, bilginin kanttlanabilirliğiyle ilgili Viyana okulu, Popper'in görüşü ve Thomas Kuhn'un görüşlerini aktarmaktadır. 
Bilgi, bilimsel yolla elde edilebildiği gibi geleneklerden, otoritelerden, bireysel tecrübelerden, yaşlılardan vd. elde edilebilmektedir (Karasar, 2005; Erkuş, 2005; Ekiz, 2003). Bilimsel yol, bilginin ortaya çıarılmasında izlenmesi gereken aşamalar olarak açıklanmaktadır. Örneğin, Karasar'a $(2005,13)$ göre bilimsel yöntem "tüme varım ve tümden gelimin sentezidir ve empiriktir". Karasar (2005, 17) devamla, Dewey'in (1933) önerdiği bilimsel yöntem aşamalarını "tümevarım, tümdengelim, sınama ve raporlaştırma" şeklinde dörde indirir. Erkuş'a (2005, 33-34) göre "bilimsel yöntem bir süreçtir ve kuram her aşamada görgül yanla iç içedir. Bu nedenle, "süreç döngüseldir ve dişa açılan helozonik bir işleyiş göstermektedir". Salkind'e $(2000,6)$ göre bilimsel araştırma süreci "soru sorma, etkenleri belirleme, hipotez geliştirme, veri toplama, hipotez test etme, hipotezi ve kuramı gözden geçirme" aşamalarından oluşmaktadır. Robson (1995, 18-19) ise, nicel araştırma ve bilimsel araştırmanın aynı anlamda olduğunu ve bilimsel yöntemin hipotezle başlayıp beş aşamadan oluştuğunu belirtmektedir.

Bu bağlamda dikkat çeken konu şudur; hem bilim hem de gelenekler, otoriteler, vs. bilgi kaynağı olarak görülmesine rağmen, geleneklerden, otoritelerden ve bireysel tecrübelerden elde edilen bilgilerin göreceli olduğu ve genellenebilirlik özelliğinin az olduğu belirtilmektedir. $\mathrm{Bu}$ durum, aşağıda açıklanacak nedenlerden dolayı biraz çelişkili görünmektedir. Eğer herhangi bir şey (otorite, bireysel tecrübe, vs.) bilim insanları tarafından bilgi kaynağ 1 olarak görülmüşse, bu kaynak(lar)dan elde edilen bilgilere karş1 önyarg1lı olunmadan ve subjektif olarak nitelendirmeden daha geniş bir bakış açısından yorumlanabilir. Bu bağlamda bilgi kaynağı olarak görülen otoriteler ve bireysel tecrübeler şu şekilde de yorumlanabilir:

Mevcut kaynaklarda, örneğin Ekiz (2003) ve Erkuş (2005) otorite kişilere örnek olarak yaşlılar, bilgeler ve din adamlarını örnek göstermiştir. Ancak bu bağlamda göz önünde bulundurulması gereken önemli bir husus vardır; bilim insanlarının kendileri de birer otoritedir. Başka bir ifadeyle, otoriteleri sayarken öğretim elemanlarını da bu grubun içine dahil etmek gereği vardır. Çünkü her öğretim elemanı (örnek Yrd. Doç. Doç. Prof.) kendi alanıyla ilgili lisans üstü çalışmalar yaparak uzmanlaşmış kişidir. Bu uzman kişilerin kendi alanlarıyla ilgili topluma açıklayıcı, bilgilendirici bilgiler vermesi, hatta kendi bireysel tecrübelerini toplumla paylaşması kadar doğal bir şey olamaz.

Örneğin, terör konusunda uzman bir akademisyen, terörle mücadele yapmak için ekonomik tedbirlerin alınması gerektiğini belirtirken, başka bir uzman, askeri ve polisiye tedbirlerle terörün önlenebileceğini belirtebilir. Bilgi kaynağı olarak görülen otorite kişilere, bir diğer örnek olarak, 
enflasyonla mücadele eden kişilerin görüşleri gösterilebilir. Ülkedeki enflasyonu düşürmek için ilgili otorite kişilerin (bakan, milletvekili,, ekonomist, köşe yazarı, vs.) enflasyonla mücadele konusunda farklı görüşler belirttikleri günlük yazılı ve görsel basın haberlerinden bilinmektedir. Bazı otoriteler, enflasyonu düşürmek için gelir-gider dengesinin (bütçenindenkleştirilmesi) eşit olmasını vurgularken, başka otoriteler de dövizin serbest kur üzerinden işlem görmesini, ithalatın vs. serbest olmasını göstermişlerdir.

Netice olarak şu söylenebilir, otorite kişi denince sadece politikacıları, din adamlarını, yaşlıları, vs. dikkate alıp, bunların dışındakileri yok saymak önemli bir eksikliktir. Otorite kişiler arasında bilim insanları, askerler, polisler, sanatçılar vardır. Kısacası her meslek grubuna ait otorite kişiler bulunmaktadır.

Bilimsel yolla elde edilen bilginin en güvenilir ve geçerli bilgi olduğu bilinmektedir ancak, bilim insanları da herhangi bir problemin (örnek, terör, enflasyon, işsizlik) çözümü konusunda farklı düşünebilmektedir. Bilimsel kitap ve makale yazarken, bilgi edinme kaynakları açıklanırken, bilgi edinme kaynaklarından birisi olan otoriteler konusu daha geniş bakış açısından düşünülüp yorumlanabilir.

Yine, bireysel tecrübe, bilgi edinme kaynaklarından biri olarak görülür (Ekiz, 2003), ancak bunun "coğrafi koşullara göre değişebileceği” (Erkuş, 2005), "sağduyu ve yaklaşımla" sinırlı olduğu belirtilmektedir (Karasar, 2005). Bireysel tecrübe kişiden kişiye değişebilir, aynı konu/problem hakkında bireysel tecrübesi olanlar farklı öneriler getirebilir. Bu bağlamda, bireysel tecrübelerin bilgi üretmede yetersiz olduğu, bilgi üretmede bilimsel yöntemin kullanılması gerektiği belirtilmektedir (Erkuş, 2005).

Bilgi üretmede, bilimsel yöntemin önemi inkar edilemez. Ayrıca, bilimsel yolla üretilen bilginin en son doğru ve genel bilgi olduğu ve bu bilginin de geliştirilebileceği bilinmektedir. Ancak bilimsel bilgi üretilirken bile, tecrübeli olmanın ve bireysel tecrübenin önemi büyüktür. Bireysel tecrübenin günlük yaşamımızda ve bilimsel çalışmalardaki önemi şu şekilde örneklendirilebilir: Tecrübeli bir aşçı ile tecrübesiz aşçının yaptığı yemeklerin tadı farklı olur. Doğada, aslanların avını yakalama olayını gözleyen yeni (tecrübesiz) bir araştırmacı ile tecrübeli bir araştırmacının gözlem notları ve aktaracakları birbirinden farklıdır. Yine, uzmanlığını yeni bitirmiş bir tıp doktorunun ameliyat yapması ile 5-10 y1llık tecrübesi olan başka bir tıp doktorunun ameliyat yapması farklıdır. Kısaca, tecrübe, bilginin elde edilmesinde ve üretiminde bir avantaj sağlar denilebilir. Rowland $(1986,26)$ bunu "bilgi tecrübe ile sabitleşir" diyerek açıklamıştır. 
Sosyal ve güncel hayatta olduğu gibi bilimsel araştırmalarda çalışılacak konuyla ilgili bireysel tecrübeye sahip olmak önemli bir unsurdur. Bireysel tecrübeye sahip olmak için çok uygulama yapmaya ve uzun bir sürece ihtiyaç duyulur. Bu nedenle, bireysel tecrübe, işe yaramaz bir şey değil, bilimsel, güvenilir ve doğru bilgiler üretmeye yardımcı olan unsurlardan bir tanesidir. Yukarıda da açıklandığı gibi, birer bilimsel otorite olan tecrübeli öğretim üyelerinin (otoriteler) genç bilim insanlarını yetişirken, bilgi birikimlerini aktarmaları kadar, uzmanlık alanlarıla ilgili tecrübelerini aktarılması da önemlidir.

Sonuç olarak şunlar ileri sürülebilir: Bilgi kaynağı olarak görülen otorite kavramı daha geniş açıdan yorumlanabilir. Bilim insanları çalıştıkları alanda birer otoritedir. Hem sade vatandaşların, hem de bilim insanlarının tecrübeye ihtiyaçları vardır denilebilir. Sadece bilimsel yolla elde edilen bilgileri değerli bulmak yerine, her kaynaktan elde edilen bilgiler değerli olabilir anlayışı daha anlamlı görünmektedir. Yine bu bağlamda, her türlü bilgi kaynağına önyargısız yaklaşarak, bu bilgileri de araştırmaya ve incelemeye değer bulmak bilimsel anlayışla örtüşmektedir.

\section{Araştırma Modelleri - Düzenekleri}

Diğer bir tartışma konusu ise bilimsel araştırmanın yapılış şekliyle ilgilidir ve bu konuyla ilgili görüşleri izah etmeden önce, araştırma teriminin temel birkaç anlamını kısaca belirtmek gerekir. Çünkü araştırmacının bakış açısı araştırmanın modelini ve türünü belirlemektedir. Karasar $(2005,22)$ araştırmayı "temelde bir arama, öğrenme, bilinmeyeni bilinir yapma, karanlığa 1şık tutma, kısaca bir aydınlanma süreci" olarak tanımlamaktadır. Kaptan $(1991,13)$ araştırmayı birkaç şekilde tanımlamaktadır. Bu tanımlar insanların ve toplumun yararına olma, bilgi ve teknoloji üretme ve bilimsel araştırma süreçlerine vurgu yapmaktadır. Nunan'a $(1994,2)$ göre araştırma "problemi kritik olarak inceleme ve değerlendirme faaliyetidir". (Salkind 2000, 326) araştırmayı "bilgi toplamak için organize edilmiş süreç" olarak görür. Robson ise $(1995,19)$ araştırmayı nitel ve nicel olarak iyiye ayırır ve amacın, nitel araştırmada bulmak, keşfetmek, nicel araştırmada ise test etmek olduğunu belirtir.

Bilimsel araştırma yöntemleri üzerine Türkiye'de hazırlanan çeşitli kitapların (örneğin, Ekiz, 2003; Balc1, 1997; Kaptan, 1991; Erkuş, 2005) ve makalelerin kaynakça kısımları incelendiğinde, bu eserlerin büyük çoğunluğunun İngilizce yazılmış kaynaklardan yararlandığı görülmektedir. Yabanc1 veri tabanları (örnek, ERIC, EBSCO, BEI, vs.) ve bilimsel araştırma konusunda İngilizce yazılmış kitapların (örneğin, Cresswell, 1994; Robson, 1996; Miles ve Huberman, 1994; Salkind, 2000) incelenmesinde 
ise, araştırmaların, İngilizce qualitative (niteliği ait, niteleyici) ve quantitative (nicel, niceliğe ait) sözcükleriyle anlatıldığı görülmektedir. Yine Türkiye'de yazılan bilimsel araştırma yöntemleriyle ilgili kaynakların bazıları, araştırma yöntemlerini sabit kategoriler altında sınıflandırmaktadırlar. Örneğin, Ekiz (2003), Çepni (2005), Yıldırım ve Şimşek'in (2005) yaptığı sinıflandırmalarda, özel durum araştırması, etnografik araştırma, aksiyon araştırması, vs. gibi araştırmalar, nitel araştırma başlığı altında yer almaktadır. Basit deneysel, yarı deneysel, gerçek deneysel araştırma türleri ise nicel araştırmanın altında yer almaktadır. Bu tür bir sınıflama, özel durum araştırması, aksiyon araştırması, etnografik araştırmanın nitel olarak yapılmasının veya araştırılmasının gerekliliğini ima etmektedir. Böyle bir anlayış çok doğru gözükmemektedir. Çünkü aksiyon araştırması, özel durum araştırması, etnografik araştırma nitel yapılabildiği gibi nicel olarak da gerçekleştirilebilir. Bu konu ile ilgili aksiyon araştırmasından çeşitli örnekler verilebilir.

Aksiyon araştırmasının nitel şekline O'brien ve diğerlerinin (2000, 4366) çalışması örnek verilebilir. Bu çalışmada, ilköğretim düzeyindeki iki dilli çocukların dil gelişimlerini desteklemede işbirlikçi ve uygulamalı olarak araştırırken, beş tane nitel soruya cevap aramışlardır. Bir diğer örnek Laidlaw'ın yaptığı çalışmadır. Üniversitede görevli Laidlaw (1994, 223241), doktora öğrencisi Sarah'a demokratik ilkelere göre nasıl danışmanlık yaptığını ve Sarah'nın da başka öğrencilere öğretirken kendi anlayışında ve uygulamalarında ne gibi değişiklikler meydana geldiğini incelemiştir. Aynı şekilde, Thorne ve Qiang (1996, 254-262) yaptıkları çalışmanın ilk aşamasında aksiyon araştırması konusunu yüksek lisans yapan öğretmenlere öğretmişler, ikinci aşamasında öğretmenlerin sınıflarda birer aksiyon araştırması uygulamalarını istemişlerdir. Pritchard'da (1995, 249-264) üç Japon öğrenciyle gerçekleştirdiği çalışmasında Japonların kültürel ve sosyal farklılıklarını aksiyon araştırması yöntemiyle incelemiştir. Bu çalışmada veri toplama aracı olarak grupla mülakat yöntemi kullanılmışır. Block (1997, 347-359) ise "dil öğrenenleri dinleyerek öğrenmek" adlı aksiyon araştırması çalışmasında iki adet soruya cevap aramıştır. Çalışmada mülakat ve günlük tutularak veriler toplanmıştır.

Aksiyon araştırmasına nicel şekline de çeşitli örnekler verilebilir. Örneğin, Philpott (1993, 191-210) öğrencilerin küçük sınıflarda oturma yerleri (ön, arka, orta) ile başarıları arasında bir ilişki olup olmadığını ve öğrencilerin sınıftaki etkinliklere karşı tutumlarını incelemiştir. $\mathrm{Bu}$ çalışmada 15 tane hipotez test edilmiştir. Sonuç olarak, öğrencilerin oturdukları yerin başarıyı etkilediği görülmüştür. Rainey ise (2000, 65-91) çalışmasında aksiyon araştırmasının dünyadaki İngilizce öğretmenleri 
arasında ne kadar yaygın olduğunu ve aksiyon araştırması konusunu bilenlerin bunları ne kadar uyguladıklarını ve uygulama sonuçlarını yazıya döküp dökmediklerini araştırmıştır. Araştırmasında 7 adet hipotez kullanmıştır. Fortune (1992, 160-171) çalışmasında yabancı dil öğrenen öğrencilerin gramer (dilbilgisi) öğrenirken tüme varım veya tümden gelim yaklaşımlarına göre yazılan gramer kitaplarından hangisini tercih ettiğini araştırmıştır. Araştırmayı gerçekleştirmek için anket düzenlemiş ve sonuçları yüzdelik (istatistiksel) olarak vermiştir.

Araştırmaların soru, amaç, hipotez kullanmasına, örneklem seçimine vs. göre sınıflandırılması doğaldır. Batılı kaynaklarda araştırma yaklaşımlarının nitel ve nicel olarak ikiye ayrıldığ ve araştırma türlerinin de nitel veya nicel gerçekleştirildiği görülmektedir. Bu yaygın ve klasik bir gruplama türüdür. Türkiye'deki bazı araştırmacılar, araştırmaları nitel ve nicel olarak gruplarken, bazı araştırmacılar ise, araştırmaların sınıflandırılmasında yeni bir isimlendirme kullanmaktadırlar. Örneğin, Kuş (2003) ilk önce, araştırmanın "pozitivist veya anlamacı" metodoloji ile gerçekleştirdiğini, daha sonra ise pozitivist yerine nicel, anlamacı yerine ise nitel kullandığını belirtmektedir. Ekiz $(2003,21)$ ise kullanılacak araştırma modelini "paradigma" olarak nitelemektedir; bunlar pozitivizm ve post-pozitivizmdir. Yazara göre pozitivizm, "objektiflik ve gerçeklik" gibi kavramlarla ifade edilen nicel bir araştırmadır, post-pozitivizm ise "subjektif ve göreceli" kavramlarla ifade edilen nitel bir araştırmadır. Çepni'ye $(2005,5)$ göre de araştırmalarda kullanılan yöntemlerin kökeninde "objektivizm ve rölativizm" olmak üzere iki felsefi görüş yatmaktadır. Araştırmaların bu klasik grupların dışında da değişik şekillerde gruplanması, bilimsel araştırma yazınını daha da zenginleştirmektedir. Bu yeni gruplamaya örnekler (Balc1, 1997; Erkuş, 2005; Karasar, 2005) da mevcuttur. Bu yeni siniflandirmalar kısaca şu şekilde açıklanabilir:

Balcı'ya $(1997,10)$ göre araştırmalar "ampirik ve temel" olmak üzere iki gruba ayrılmaktadır. İlkinde, araştırmacı "sadece gözlem ve betimleme değil, aynı zamanda problemin doğasını açıklama ve onun hakkında kestirim yapar". Sonrakinde ise "genel bilimsel terimlerle dünya anlatılmaya çalışılır".

Erkuş $(2005,49)$ "bakış açısına göre değişebilen araştırma sınıflaması yerine, araştırma düzeneklerine göre yapılacak bir sınıflama daha anlaşılır, somut ve kapsayıcı olacağını" belirtmektedir. $\mathrm{O}$, araştırma düzeneklerini ulaşmayı amaçladıkları hedefler açısından "ilişki aramayan ve ilişki arayan" şeklinde ikiye ayırır. İlişki aramayan çalışmalar "betimsel çalışmalar", ilişki arayan çalışmalar ise "ilişkisel ve deneyseldir" Erkuş (2005, 51). Betimsel çalışmalarda, "özellikle aniden meydana gelen herhangi bir gelişmeden 
(doğal değişimleme) sonra, o doğal değişimlemeye maruz kalan grubun davranışlarına ilişkin ölçüm almaya dayanır". Yazar "betimsel çalışmaların, olanı, olduğu gibi saptamaya (...) çalışan, farklılık ya da ilişki bulmaya çalışmayan çalışmalar oldukları için, ayrıca kendine özgü düzenekleri yoktur" demektedir.

Ancak bir çalışmanın betimsel yapılmasından söz edilirken istatistiki betimsel ile sözel (nitel) betimsel arasındaki fark belirtilmelidir. İstatistiki betimsel çalışmada, veriler, rakamsal, yüzde, korelasyon, ortalama, mod, medyan, vs. şeklinde yorumlanır (Karasar 2005, 64). Nitel betimsel araştırma ise, "çalışılan şeyin mevcut durumunun açıklanması/betimlenmesi" demektir (Salkind 2000, 192). Hatta yazar, bunu "yaptığınız tek şey okuyucunuz için resim tablosu yapmaktır" diyerek açıklamaktadır. Yani, çalışmanın yazıyla, sözcüklerle ve tümcelerle resim tablosu gibi tasvir edilmesi demektir. Örneğin, çalışmayı Eğitim Fakültesi'nde gerçekleştirdim demek yerine "eğitim fakültesine asfalt bir yol ile gidilir, dışı açık mavi boyalı, önünde iki adet bayrak direği, ve dört katlı olan bina doğu-batı istikametinde yapılmıştır. Zemin kat laboratuar ve atölyelerden, birinci ve ikinci katların ise dersliklerden oluştuğu görülmektedir...vb". Bu tür tasvirde, bina, öğrenciler, öğretim elemanları, çalışma, vs. resim tablosu gibi tasvir edilir.

Erkuş $(2005,74)$ "nitel araştırma şeklinde adlandırılan araştırmaların hepsinin betimsel araştırma" olduğunu" belirtmektedir. Ancak, yukarıda açıklandığı gibi, yapılan çalışmanın, istatistiki betimsel mi yoksa nitel betimsel mi olduğunun belirtilmelidir. Erkuş $(2005,68)$ devamla "deneysel araştırmalarda deney ve kontrol grubu neden-sonuç ilişkisine bakılır. İlişkisel araştırmalar, nedensellik dışı ilişki arar, mutlaka korelasyon analizi yapılmaz, neden-sonuç ilişkisi kurulamayan, değişim veya denetimin yapılamadığı veya kısmen yapıldığ1 çalışmalara yarı-deneysel veya özel amaçlı deneysel çalışmalardır" demektedir.

Karasar (2005, 23) araştırma türlerini "temel ve uygulamalı" araştırmalar olmak üzere ikiye ayırır ve temel araştırmaların amacının "var olan bilgiye yenilerini katmak" olduğunu belirtir, ancak uygulamalı araştırmalar sonunda da yeni bilgiler üretilebileceği bilinmektedir. Yazara göre temel araştırmalar "açımlama, ayrıntı saptama, neden-sonuç ilişkisi ve kuram geliştirme düzeylerinden oluşmaktadır (s.24-26). Uygulamalı araştırmaları ise "aksiyon araştırması ve AR-GE araştırmaları" olarak ikiye ayırmaktadır (s.27-28), ancak diğer araştırma türlerinden (aksiyon araştırması, tarihsel araştırma, vd.) bahsedilmemektedir. 
Karasar'a $(2005,77-87)$ göre araştırma modelleri "tarama ve deneme" biçimlerindedir. İlkinde, "geçmişte ya da halen varolan bir durum varolduğu şekliyle betimlenmeye çalışılır, (...) olay, birey ya da nesne, kendi koşulları içinde ve varolduğu gibi tanımlanmaya çalış1lır. Onları, herhangi bir şekilde değiştirme, etkileme çabası gösterilmez". Yazarın burada anlatmak istediği şey, başka bir ifadeyle, betimsel (tasvirsel) çalışmalardır, ancak yine bu noktada çalışmanın istatistiki betimsel mi yoksa sözel betimsel mi yapıldığı belirtilmelidir. Deneme modelinde "neden-sonuç ilişkilerini belirlemeye çalışmak amacı ile, doğrudan araştırmacının kontrolü altında, gözlenmek istenen veriler üretilir". Bu modelde "gözlenmek istenenlerin araştırmacı tarafından üretilmesi söz konusudur. Amaçlar genellikle denence (hipotez) şeklinde ifade edilir. Böylece, olayların olası nedenlerine ilişkin yargılar sınanmış olur".

Görüldüğü gibi bilimsel araştırma yaklaşımları yaygın olarak nitel ve nicel olarak ikiye ayrılmaktadır ve nicel araştırma ile bilimsel araştırma eş anlamda kullanılmaktadır. Araştırmanın nitel veya nicel oluşunu, araştırmacının bakış açısı, araştırma hipotezi, soruları ve amaçları belirlemektedir. Nitel ve nicel araştırmalarla ilgili yaptığımız tespit şudur: Sosyal, olgu, olay, insan ve durumun nitel yolla araştırılması daha makul gibi gözükmektedir. Çünkü sosyal olayların, insanların, olguların nicel olarak hipotezlerle araştırılmaya başlanması, "hastayı muayene etmeden reçete yazmaya benzemektedir" (Tomakin 2001, 122). Bu ise, iş, emek, zaman, para, insan, vs. kaybı ve telafisi imkansız zarar gibidir. Ayrıca, araştırma türleri (aksiyon araştırması, etnografik araştırma, vd.) hem nitel hem de nicel olarak gerçekleştirilebilir. Son olarak, araştırma yaklaşımları ve türlerinin klasik ve yaygın sınıflanmasından başka temel, uygulamalı, ilişki arayan ilişki aramayan araştırmalar gibi sınıflandırıldığı görülmektedir.

\section{3- Yaklaşım, Yöntem ve Tekniklerin Belirtilmesi}

Yukarıda da belirtildiği gibi, yapılan araştırmalar nitel ve nicel olarak iki ana gruba ayrılmaktadır. Yine, araştırma türleri olarak deneysel, aksiyon araştırması, özel durum araştırması, temellendirilmiş teori, tarihsel araştırma, vs. şekillerinde gerçekleştirilmektedir. Araştırma düzenin nitel veya nicel olması durumuna göre de toplanan veriler analiz edilip yorumlanmaktadır. Aşağıda da görüleceği gibi, hem ülkemizde hem de yurt dışında yapılan bazı çalışmalarda kullanılan yaklaşım, yöntem ve tekniğin ayrı ayrı belirtilmediği görülmektedir. Örneğin, "çalışmamız betimseldir ve anket uygulanmıştır" denilmektedir. Karasar'ın (2005) ve Salkind (2000) belirttikleri gibi betimsel bir çalı̧̧ma istatistiki olabildiği gibi sözel betimsel de olabilmektedir. $\mathrm{Bu}$ bağlamda, yaklaşım, yöntem ve teknik kavramlarının anlamı burada kısaca belirtmek gerekir. Çünkü Türkçe'ye başka dillerden geçen bazı kavramlar 
bazen yanlış anlaşılabiliyor veya kişiler bu kavramları kendi görüşleri doğrultusunda açıklama yolunu tercih edebiliyorlar. Bu nedenle, bilimsel araştırma yöntemleri ile ilgili eserlerin çoğunluğu İngilizce kitap ve makalelerden yararlanılarak yazıldığı için, yaklaşım, yöntem ve teknik kavramları da İngilizce Oxford Advanced Learner's Dictionary'deki kullanıma göre açıklanmıştır.

Türkçe'de yaklaşım sözcügünün İngilizce karşılığ “ "approach"dır ${ }^{1} v e$ "bir şeyi yapma yolu" anlamında kullanılır. Başka bir ifadeyle, bir şeyi yapma modeli, usulü, ve ilkesi olarak ta çevrilebilir. Bu bağlamda yaklaşım sözcüğünün araştırmacının bakış açısını yansıtan genel bir ifade olduğu görülmektedir. Özellikle yabancı veri tabanlarında ve ülkemizdeki bir çok çalışmada bu genel tanıma uygun nitel (qualitative) ve nicel (quantitative) sözcüklerinin kullanıldığını görmekteyiz. Bu da araştırmacının, yapacağı çalışmayı "bu çalışma nitel yapılır/yapılmalı" veya "bu çalışma nicel yapılır/yapılmalı" şeklindeki ön kabullerini ve düşüncesini belirtmesi demektir.

İngilizce "method"2 sözcüğü ise "bir şeyi belli bir şekilde yapmak" olarak çevrilebilir. Yaklaşım tanımına göre, metot (yöntem) tanımı daha net ve spesifiktir. $\mathrm{Bu}$ da, araştırmacının çalışmasını daha belirgin şekilde/türde ifade etmesi olarak yorumlanabilir. Yani, araştırmanın türü, nerede yapılacağ1, ne yapılacağı ve nasıl çalışılacağ 1 belirlenir. Araştırma doğada çalışılacaksa etnografik araştırma, değişiklik-yenilik yapılacaksa aksiyon araştırması, değişkenler üzerinde uygulama yapılacaksa deneysel bir çalışma olur. Son olarak da araştırmada kullanılacak tekniğinin/tekniklerinin belirlemesi gerekir.

İngilizce "technique"3 sözcüğü ise "özellikle bilimde veya sanatta, bir şeyi belli bir yönteme göre yapmak/icra etmek" olarak çevrilebilir. Buradan da tekniğin, yöntem ölçüt/kıstas alınarak yapıldığ1 ve yöntemin bir alt derecesi olduğu anlaşılmaktadır. Örneğin, eğer nicel bir araştırma yapılıyorsa, kullanılabilecek teknikler, f-testi, t-testi, yüzde (\%), frekans, mod, medyan, standart sapma, vs. olabilir. Nitel bir araştırma yapılıyorsa kullanılabilecek teknikler transkript, kodlama, açık kodlama (open coding), karşılaştırma, gruplama, benzerliklere veya farklılıklara bakma, kategorilere ayırma vs. olabilir.

\footnotetext{
1 1. Approach: a way of dealing with sb/sth; a way of donig sth, (s.49)

${ }^{2}$ Method: a particular way of doing sth, (s.734)

${ }^{3}$ Technique: a method of doing or performing sth. esp. in arts and sciences, (s.1276)
} 
Yapılan herhangi bir çalışmada yaklaşım, yöntem ve tekniklerin belirtilmesi gerekirken, hem yurt dışında, hem de Türkiye'de yapılan bazı çalışmalarda bu hususun bazen dikkate alınmadığı şu örneklere bakılarak görülebilir. Armstrong (1992-1993) Evdeki Dili (anadili) Okulda Kullanmak adlı makalesinde, öğrencilerin yabancı dil öğrenirken utangaç ve isteksizlik problemlerini gidermek için, hikayeleri çocukların önce anadilinde (Gujarati) sonra da İngilizce olarak öğretmeye çalışmıştır. Bu çalışma, bir aksiyon araştırmasıdır, ancak makalede metot/metodoloji kısmı bulunmamaktadır. Çalışma rakam ve istatistikten ziyade tümcelerle ve sözcüklerle ifade edildiğinden, nitel yaklaşımının kullanıldığı anlaşılmaktadır. Bir diğer örnek Sargeant'ın (1993, 6-13) çalışmasıdır. Bu, "Okullarda Tartışmayı Öğretmenin Meta-etiği: Cinsiyet ve Güç" adlı bir aksiyon araştırmasıdır, ancak bir başlık altında yazılmış metot veya metodoloji bölümü bulunmamaktadır. Çalışmanın, yazıyla ve sözcüklerle anlatıldığı için nitel yaklaşımla yapıldığı anlaşılmaktadır. Benzer şekilde Irshad ve Imrie, (1997: 15-17; Nunan, 996: 35-41; Cumming, 1991: 181200, Johnstone'un, 1990: 22-25) yaptıkları çalışmalarda metot/metodoloji bölümleri bulunmamaktadır. $\mathrm{Bu}$ çalışmaların birer aksiyon araştırması olduğu belirtilmiş, data toplama ve analiz şekilleri de birkaç tümce ile kısaca anlatılmıştır.

Türkiye'de yapılan bazı çalışmalarda da, araştırmada kullanılan yaklaşım, yöntem veya teknikten bir veya birkaçının belirtilmediği görülmektedir. Şahin'in $(2007,1-8)$ çalışmasında metot/metodoloji bölümü ihmal edilmiştir. Çalışmalar kuramsal yapılsa bile, sözcük ve tümcelerle anlatılıyorsa nitel bir yaklaşım kullanılıyor demektir ve bu belirtilmelidir. Ayrıca, araştırmanın türü de (etnoğrafik, özel durum, aksiyon araştırması, tarihsel araştırma, vs.) belirtilmemiştir. Şahin'in çalışması, motivasyon ile sınırlandırıldığı için çalışmanın yöntemi "case study"dir. Çalışmada kullanılan teknik belirtilmemiştir, ancak çalışmanın literatür taramasına dayalı olarak gerçekleştirildiği anlaşılmaktadır. Bölükbaş (2004, 19-28) ve Öz'ün (2006, 68-84) çalışmalarında, Şahin'in (2007) çalışmasındakine benzer metot/metodoloji sıkıntılar göze çarpmaktadır. Aynı şekilde Bekleyen' in $(2004,38-47)$ çalışmasının yöntem bölümünde sadece örneklem ve veri toplama şekli belirtmiştir. Veri analizinde t-testi, ANOVA ve Scheffe tekniklerin kullanılmasından, çalışmanın nicel yaklaşım kullanılarak yapıldığı iddia edilebilir. Çalı̧̧ma hem istatistiki tablolarla hem de sözcük ve tümcelerle anlatıldığı için çalışmada nitel ve nicel yaklaşımlar ortak kullanılmıştır. Ayrıca çalışmanın türü hakkında bilgi vermemektedir. Tavil ise (2006) çalışmasının yöntem bölümünde uyguladığı anketi SPSS paket programı ile analizi nasıl yaptığını belirtmektedir, ancak çalışmanın yaklaşımı ve türü belirtilmemektedir. İlter ve Er (2007, 21-30) erken yaşta 
yabancı dil öğretimiyle ilgili veli ve öğretmen görüşleri üzerine yaptıkları çalışmada anket çalışması yaptıklarını ve verileri SPSS aracılığıyla frekans ve yüzde uyguladıklarını belirtmektedirler. Çalışmada kullanılan yaklaşım ve araştırma türü belirtilmemiştir.

Sonuç olarak: Türkiye'de onlarca hakemli dergi bulunmaktadır ve bu dergilerde yayımlanan araştırmaların hepsini bilimsel araştırma yaklaşımı, yöntemi ve tekniği açısından incelemek makul ve olanaklı değildir. $O$ nedenle, bu çalışmada, bilimsel araştırmalarda ve yayınlarda bunların belirtilmesinin bir gereklilik olduğu bir kez daha araştırmacılara hatırlatılmaktadır. Çünkü bilimsel bilginin özelliklerinden bir tanesinin tekrarlanabilirlik olduğu bilinmektedir. Yani, bir bilimsel çalışma sonucu ortaya çıkan bilgi başkaları tarafından da aynı yöntemle aynı şekilde elde edilmesi gerekir. Bilginin tekrarlanabilir ve genellenebilir olması, o bilginin bilimsel olduğunu göstermektedir. $\mathrm{Bu}$ nedenle, yapılan çalışmalarda kullanılan yaklaşımlar, yöntemler ve teknikler açık ve net olarak belirtilmezse, başka araştırmacılar bu bilgilerin doğruluğu sınayamazlar/araştıramazlar. Yani, araştırmada kullanılan yaklaşım, yöntem ve teknik gizlenemez ve araştırma sonuçlarının yazımında ihmal edilemeyecek kadar önemlidir.

\section{SONUÇLAR}

\section{Genel Sonuçlar}

Bilimsel araştırma, bilimsel yaklaşım, araştırma modelleri, vs. konularındaki tartışmalara rağmen, bilim hızlı şekilde ilerlemektedir. Bilimsel araştırma yapma konusunda önceden beri var olan ve halen devam eden iki temel görüş vardır. Bunlar da araştırmanın nitel mi yoksa nicel mi yapılacağıdır. Sadece nicel yolla elde edilen bilgiler değil, aynı zamanda nitel yolla elde edilen bilgiler de bilimseldir. $\mathrm{Bu}$ çalışmada kullanılan kaynaklar dikkate alınarak, nitel ve nicel araştırmayla ilgili şu ilkeler ifade edilebilir.

Nicel araştırmalar hipotezle başlar ve araştırma boyunca hipotez test edilir.

Nicel araştırmalar tümden gelim yaklaşımını kullanırlar.

Nicel araştırmada amaç, hipotezi test etmektir.

Nicel araştırmalarda deney ve kontrol grubu vardır.

Nicel araştırmalarda örneklem rastgele seçilir.

Nicel araştırmalarda sonuçlar evrene genellenir.

Nicel araştırma sonuçlarının kuvvetli olduğuna inanılır.

Nicel araştırmalar genellikle rakamlarla, tablolarla ve istatistiki olarak ifade edilir.

Nitel araştırmalar amaç veya sorularla başlar. 
Nitel araştırmalar tüme varım yaklaşımına göre gerçekleştirilirler.

Nitel araştırmalarda amaç, bulmak, keşfetmek, ortaya çıkarmaktır.

Nitel araştırmalarda amaçlı örneklem seçimi vardır.

Nitel araştırmalarda sonuçlar dolaylı olarak ve benzer olaylara genellenir.

Nitel araştırma sonuçlarının zayıf olduğu iddia edilir.

Nitel araştırmalarda süreç veri toplama, veri analizi ve sonuç çıkarma şeklinde olmaktadır.

Nitel araştırmalar genellikle yazıyla, sözcük ve cümlelerle ifade edilirler.

$\mathrm{Bu}$ genel ilkelerin belirtilmesi özellikle yeni araştırmacılara faydalı olabilir ve onların, araştırma yaparken zaman, emek, vs. kaybını önleyebilir.

\section{2. Çalışmanın Amaçlarıyla İlgili Sonuçlar}

1) Bilgi kaynakları çeşitlidir ve bunlar arasında en güvenilir ve geçerli olanı bilimsel yolla elde edilen bilgidir. Ayrıca bilimsel yöntemin dışında tutulan bilgi kaynaklarının (örneğin, bireysel tecrübe, otoriteler, vd.) hem günlük ve sosyal yaşantımızda hem de bilimsel araştırmalarda etkisi olduğu görülmüştür. Bütün bilgi kaynaklarının bilim insanları tarafından dikkate alınması ile daha çok ve daha yararlı bilimsel çalışmalar yapılabilir.

2) Bilimsel araştırma türlerinin (etnografik, aksiyon, tarihsel, vd.) sınıflandırılmasında, araştırmaların hem nitel hem de nicel olarak yapıldığı görülmektedir. Türkiye'de 100'e yakın üniversite ve araştırma yapan binlerce akademisyen bulunmaktadır. Araştırma türlerinin her iki grupta (nitel veya nicel) yapılabiliyor olmasını göstermek, özellikle yeni araştırmacılara yararlı olabilir. Bir araştırma türünün nitel veya nicel olmasını, araştırmacının bakış açısı belirlemektedir. Amaç, hipotez(ler) test etmek ise, araştırma nicel; amaç, bulmak, keşfetmek, açıklamak ise araştırma, nitel yapılır.

3) Yapılan araştırmaların ve yayınlanan makalelerin metot bölümlerinin metodoloji olarak yazılması daha uygun olabilir. Çünkü bir araştırmada birden çok yaklaşım kullanılabilir. Örneğin, araştırmada nitel ve nicel yaklaşımlar ortak olarak kullanılabilir. Aynı şekilde bir araştırmada birden çok yöntem kullanılabilir. Örneğin, amacı, Güney Afrika'da yaşayan kabilelerin düğün geleneklerinin incelenmesi olan bir araştırma, hem etnografiktir hem de "case study"dir. Çalışma, düğün yapma kültürünü incelendiği için etnografiktir, Güney Afrika ile sınırlandırıldığı için "case study"dir. Aynı şekilde, araştırmalarda birden çok teknik kullanılır ancak, tekniğin, yöntemin ve yaklaşımın birbiriyle uyumlu olması gerekmektedir. 


\section{KAYNAKLAR}

Armstrong, D. (1992) Using Home Languages in School- an Action Research Project, Language Issues, Vol. 5, No (2) 7-9.

Balcı, A. (1997) Sosyal Bilimlerde Araştırma, Yöntem, Teknik ve İlkeler, (İkinci Bask1), Ankara: 72 TDFO Bilgisayr-Yayıncılık San. Tic. Ltd. Şti.

Bekleyen, N. D. (2004) İngilizce Öğretmen Adayları Tarafindan Kullanılan Dil Öğrenme Stratejileri, Elektronik Sosyal Bilimler Dergisi, ISSN: 1304-0278, Cilt;3, Say1; 10, ss.38-47

Bell, J. ve diğerleri (1984) Retinking Case Study, Conducting Small Scale Investigations in Educational Management, ssLondon: London: P. C. Publishing, 93-102.

Block, D. (1997) Learning by listening to language learners, System, Vol. 25, No (3) 374-360.

Bölükbaş, F. (2004) Dünyada Türkçe Öğretimi 6, (15-16 Nisan) Ankara: Bildiri olarak sunulmuştur.

Cohen, L. ve Manion, L. (1996) Research Methods in Education, $\left(4^{\text {th }}\right.$ edition), London: Routledge.

Creswell, J. W. (1994) Research Design. Qualitative and Quantitative Approaches, London: Sage.

Cumming, A. \& Gill, J. (1991) Learning ESL Literacy Among IndoCanadian Women, Language Culture and Curriculum, Vol. 4, No (3), 181-200.

Çepni, S. (2005) Araştırma ve Proje Çalışmalarına Giriş, (2. Bask1), Trabzon: ISBN 975-417-000-2.

Ekiz, D. (2003) Eğitimde Araştırma Yöntem ve Metotlarına Giriş, Anı: Ankara.

Erkuş, A. (2005; Bilimsel Araştırma Sarmalı, Ankara: Seçkin.

Fortune, A. (1992) Self-study grammar practice: learners' views of preferences, ELT Journal, Vol. 46, No (2) 160-171.

Irshad, K. \& Imrie, J. (1997) Improving Attainment Through Action Research: an introduction to Hillingdon's Raising Achievement Project, Multicultural Teaching to Combat Racism in School and Community, Vol. 15, No (2), 15-17. 
İlter, B. G. ve Er, S. (2007) Erken Yaşta Yabancı Dil Öğretimi Üzerine Veli ve Öğretmen Görüşleri, Kastamonu Eğitim Dergisi, Cilt: 15, No (1) 2130 .

Johnstone, R. (1990) Action-research in the Foreign Language Classroom, Language Learning Journal, Vol. (1), 22-25.

Kaptan, S. (1991) Bilimsel Araştırma ve İstatistik Teknikleri, Ankara: Tekışık Web Ofset Tesisleri.

Karakaş, S. (1988) Bilimsel Psikoloji: Temel İlkeler, Ankara: TBMM Vakfı Ofset Tesisleri.

Karasar, N. (2005) Bilimsel Araştırma Yöntemi, Ankara: Nobel

Kuş, E. (2003) Nitel-Nicel Araştırma Teknikleri, Anı: Ankara.

Laidlaw, M. (1994) The Democratising Potential of Dialogical Focus in an Action Enquiry', Educational Action Research, Vol. 2, No (2), 223-241.

Miles, M. B \& Huberman, A. M. (1994b) Qualitative Data Analysis: An Expanded Book, (2 $2^{\text {nd }}$ edition), California: Thousand Oak, CA.

Miles, M. B. \& Huberman, A. M. (1984) Drawing Valid Meaning from Qualitative Data: Toward a Shared Craft, Educational Researcher, Vol. (13), 20-30.

Nunan, D. (1994) Research Methods in Language Learning, ( $3^{\text {rd }}$ edition), Cambridge: Cambridge University Press.

Nunan, D. (1996) Learner Strategy Training in the Classroom: An Action Research Study, TESOL Journal, Vol: 16, No (1), 3541.

O'Brein, et al. T. (2000) 'Collaborative Practice-based Research in Supporting the Language Development of Primary Level Bilingual Children: a case study', Educational Action Research, Vol. 8, No.1, pp. 43-66.

Oxford Advanced Learner's Dictionary (1995) Oxford: Oxford University Press.

Öz, Ö. (2006) The Use of Literature for a Constructive Basis in Language Teaching, Elektronik Sosyal Bilimler Dergisi, ISSN:1304-0278, Cilt:5, Sayı (16), Bahar.

Philpott, P. (1993) Seating Patterns in Small Language Classes: an example of action research, British Educational Research Journal, Vol. 19, No (2), 191-210. 
Pritchard, M. O. P. (1995) Amae and the Japanese learner of English: an AR project, Language Culture and Curriculum, Vol. 8, No (3), 249-264.

Punch, K. F. (1998) Introduction to Social Research, London: Sage.

Rainey, I. (2000) Action Research and the English as a Foreign Language Practitioner: time to take stock, Educational Action Research, Vol. 8, No (1), 65-91.

Robson, C. (1995) Real World Research, Cambridge: Blackwell.

Rowland, S. (1986) An Approach to Understanding Children, içinde Action research in Classroom and Schools, (editör) Hustler ve diğerleri, London: Allen \& Unwin Pres, 25-36.

Salkind, N. J. ( 2000), Exploring Research, (4th Edition), London: Prentice Hall International.

Sargeant, J. (1993) Gender and Power: The Meta-Ethics of Teaching Argument in Schools, Curriculum, Vol. 14, No (1), 6-13.

Speake, J. ve Mitchell, S. (1979) A Dictionary of Philosophy, London: Macmillan.

Stake, R. E. (1995) The Art of Case Study Research, London: Sage Publications.

Şahin, S. (2007) Driving Key for Effective Learning: Motivation, Gaziantep Üniversitesi Journal of Social Sciences, Cilt:6, Say1:(1), 1-8

Tavil, Z. M. (2006) Hacettepe Üniversitesi İngilizce Hazırlık Okulu Öğrencilerinin Okuma İhtiyaçları, Gazi Eğitim Fakültesi Dergisi, Cilt 26, Say1 (3), 207-221.

Thorne, C. \& Qiang, W. (1996) Action Research in language teacher education, ELT Journal, Vol. 50, No (3), 255-262.

Tomakin, E. (2001) An Investigation of Introduction of Action Research in English Language Classrooms and the Barriers to Its Use, (Unpuhlished PhD), Noriwch: Universtiy of East Anglia, School of Education and Professional Development.

Tozlu, N. (1997) Eğitim Felsefesi, İstanbul, MEB Yayınları.

Türkdoğan, O. (1995) Bilimsel Değerlendirme ve Araştırma Metodolojisi, İstanbul: MEB Yayınları.

Yıldırım, A. ve Şimşek, H. (2005) Sosyal Bilimlerde Nitel Araştırma Yöntemleri, Ankara: Seçkin. 